Article

\title{
Benford's Law for Telemetry Data of Wildlife
}

\author{
Lasse Pröger $^{1}\left(\mathbb{D}\right.$, Paul Griesberger ${ }^{1}\left(\mathbb{D}\right.$, Klaus Hackländer $^{1}\left(\mathbb{D}\right.$, Norbert Brunner ${ }^{2}$ and Manfred Kühleitner $^{2, *(\mathbb{D})}$ \\ 1 Department of Integrative Biology and Biodiversity Research, Institute of Wildlife Biology and Game \\ Management, University of Natural Resources and Life Sciences, Vienna (BOKU), 1180 Vienna, Austria; \\ Lasse1708@web.de (L.P.); paul.griesberger@boku.ac.at (P.G.); klaus.hacklaender@boku.ac.at (K.H.) \\ 2 Department of Integrative Biology and Biodiversity Research, Institute of Mathematics, University of Natural \\ Resources and Life Sciences, Vienna (BOKU), 1180 Vienna, Austria; norbert.brunner@boku.ac.at \\ * Correspondence: manfred.kuehleitner@boku.ac.at
}

check for

updates

Citation: Pröger, L.; Griesberger, P.; Hackländer, K.; Brunner, N.; Kühleitner, M. Benford's Law for Telemetry Data of Wildlife. Stats 2021, 4, 943-949. https://doi.org/10.3390/ stats 4040055

Academic Editor: Claudio Lupi

Received: 4 October 2021

Accepted: 18 November 2021

Published: 20 November 2021

Publisher's Note: MDPI stays neutral with regard to jurisdictional claims in published maps and institutional affiliations.

Copyright: (c) 2021 by the authors. Licensee MDPI, Basel, Switzerland. This article is an open access article distributed under the terms and conditions of the Creative Commons Attribution (CC BY) license (https:// creativecommons.org/licenses/by/ $4.0 /)$.

\begin{abstract}
Benford's law $(B L)$ specifies the expected digit distributions of data in social sciences, such as demographic or financial data. We focused on the first-digit distribution and hypothesized that it would apply to data on locations of animals freely moving in a natural habitat. We believe that animal movement in natural habitats may differ with respect to $B L$ from movement in more restricted areas (e.g., game preserve). To verify the BL-hypothesis for natural habitats, during 2015-2018, we collected telemetry data of twenty individuals of wild red deer from an alpine region of Austria. For each animal, we recorded the distances between successive position records. Collecting these data for each animal in weekly logbooks resulted in 1132 samples of size 65 on average. The weekly logbook data displayed a BL-like distribution of the leading digits. However, the data did not follow $B L$ perfectly; for $9 \%$ (99) of the 1132 weekly logbooks, the chi-square test refuted the BL-hypothesis. A Monte Carlo simulation confirmed that this deviation from $B L$ could not be explained by spurious tests, where a deviation from $B L$ occurred by chance.
\end{abstract}

Keywords: Benford's law (BL); logbook; habitat use; Monte Carlo simulation; red deer (Cervus elaphus); telemetry

\section{Introduction}

Benford's law (BL) proposes that the first nonzero digits of certain data (in decimal notation) are distributed according to (1). If $d=1,2,3, \ldots, 9$, then the probability $\operatorname{Prob}(d)$ that $d$ is observed as the first nonzero digit is $\left(\log _{10}\right.$ is decadic logarithm):

$$
\operatorname{Prob}(d)=\log _{10}(d+1)-\log _{10}(d)
$$

The probabilities decrease from $30 \%$ for $d=1$ to $5 \%$ for $d=9$. Newcomb [1] proposed $B L$ to explain why the initial pages of the logarithmic table books, the main computational tool at that time, were dirtier than the later ones. Initially, he had expected that each digit would occur with the same probability of $11 \%$. Benford [2] rediscovered this curiosity and launched a highly active [3] research program to identify data that would obey $B L$. This research was applied to identify data corruption in social sciences [4]. Starting with [5-7], deviations from $B L$ were used to expose possible cases of tax evasion [8], election fraud [9], fabrication of clinical data [10], or misrepresentation of data in government statistics [11]. There are further examples in other fields, such as astrophysics [12], atomic physics [13], biochemistry [14], library science [15], material sciences [16], theology [17], or epidemiology [18], where a recent application used BL to identify distorted COVID-19 counts [19].

Starting with Hill $[20,21]$, another line of research sought to find theoretical explanations for BL; c.f. [22]. However, he cautioned that real data may not fulfil BL exactly. For instance, exponentially distributed random variables were shown to satisfy $B L$ approximately $[23,24]$. In addition, there are related phenomena with $B L$-like distributions that 
were explained from power laws $[25,26]$ developed criteria when $B L$-like distributions may be expected.

The present study may be motivated from literature describing animal movement by stochastic processes. For instance, certain random walks (Lévy flights) were used to model the movement of deer and reindeer [27,28], and Schürger [29] explained a relation between random walk theory and $B L$. However, a fine-grained analysis of animal movement refuted the Lévy flights hypothesis [30]. We therefore ask whether the movement of deer displays $B L$-like phenomena, for alternative mechanisms leading to $B L$ are conceivable. For instance, in dynamical system theory, systems with attractors often follow $B L$ [31]. During winter, feeding stations may be attractors for the movement of game in the habitat, and these attractors may facilitate $B L$.

For red deer (Cervus elaphus), there is a large body of literature on movement ecology based on telemetry data (Google Scholar: about 5000 papers). We used such data to keep for each animal a logbook to record distances moved. By the analogy to drivers' logbooks that were shown to fulfil $B L$ [32], we hypothesized that, under natural conditions, the records of animals would obey $B L$. As to possible applications of this hypothesis, deviations of logbooks from $B L$ may indicate restricted mobility due to environmental deterioration (e.g., fragmentation of the landscape), sickness of animals, or location errors due to bad satellite reception; c.f. [33]. As the use of telemetry is common in studies of wildlife and in fisheries research, our hypothesis, if true, would establish a new topic of research within the field of movement ecology. In this paper, we tested this hypothesis.

\section{Materials and Methods}

\subsection{Data}

Data came from a collaborative project [34] of two scientific and two business partners: Institute of Wildlife Biology and Game Management (University of Natural Resources and Life Sciences, Vienna), Research Institute of Wildlife Ecology (University of Veterinary Medicine, Vienna), Gutsverwaltung Fischhorn GmbH \& Co KG, and Gletscherbahnen Kaprun AG. The project site covered about $4.2 \mathrm{~km}^{2}$ at altitudes between 880 and $3000 \mathrm{~m}$ above sea level in the valley of Kaprun (province of Salzburg, Austria). It was adjacent to the core area of Upper Tauern National Park.

Data were collected during 2015-2018. For details, see [35]. In consultation with the authorities, twenty wild red deer (ten males and ten females) with estimated ages between three and twenty years were selected at random, immobilized with a tranquilizer gun, and equipped with Global Positioning System (GPS) collars. Each device was used for a single animal. The sex, estimated age, and estimated weight of each animal were recorded when it received the GPS device.

Position recordings were taken every 2 hours and 15 minutes, saved on the collar, and transmitted to a ground station once a day per SMS. Owing to the timespan between successive measurements, we expected that successive positions of an animal would be stochastically independent of each other (for example, animals would alter their velocity, pause for grazing, and change their directions at random). There were time gaps, e.g., due to missing GPS signals. For May and June, there were no data, and for a few days of October 2016, signals were sent every 15 minutes. Further, different animals were observed through different periods of time (but there were large overlaps).

GPS-signals informed us about the $x, y$, and $z$-positions according to the WGS84 coordinate system [36], and time $t$. Based on the changes in position between two consecutive signals, the distances between consecutive signals (i.e., lengths of walks) were computed:

$$
\sqrt{\left(x_{i+1}-x_{i}\right)^{2}+\left(y_{i+1}-y_{i}\right)^{2}+\left(z_{i+1}-z_{i}\right)^{2}}
$$

The GPS data were saved in spreadsheets (Microsoft Excel 365). For each animal, we obtained a list that recorded (in row $i$ ) the position coordinates $\left(x_{i}, y_{i}, z_{i}\right)$, the time $\left(t_{i}\right)$, and (starting with row 2 ) the distance (2) to the previous position. The leading nonzero digits 
of the successive distances were also computed in the spreadsheet. If the time between two consecutive measurements exceeded one day, this distance was discarded. Distance 0 (one observation) was ignored.

As the behavior of animals differed between seasons, for each animal, we split the data into weekly logbooks. We used Mathematica software [37] to collect the weekly data and count the leading digits of the distances. The output was a spreadsheet. It displayed how often each number from 1 to 9 was the leading digit for each animal and week. Both mentioned spreadsheets are provided in the Supporting Information.

\subsection{Statistics}

To identify deviations of data from $B L$, we used multiple tests. The common measures to identify a deviation of data from $B L$ is chi-square $\chi^{2}$, defined by the equation:

$$
\chi^{2}=\sum_{\text {digits }} \frac{(\text { observed }- \text { theoretical })^{2}}{\text { theoretical }}
$$

The use of the chi-square test has been criticized in literature for various reasons, such as the "large $n$ problem" [38,39], which matters for our data, too. If we aggregate the data of all animals, we get a large sample ("large $n$ design") with 73,393 distances (first digits); for the data of each animal, there were between 431 and 7738 distances. In this context, $[4,40]$ proposed $M A D$, Equation (4), as test statistic: "What is needed is a test that ignores the number of records. The mean absolute deviation (MAD) test is such a test [...]."

$$
M A D=\sum_{\text {digits }} \frac{\mid \text { observed }- \text { theoretical } \mid}{\text { sample size } \times \text { number of digits }(=9)}
$$

However, [41] pointed out limitations for $M A D$. Further, [42] found that "a fixed 'critical value' for the MAD irrespective of the sample size may lead to biased conclusions." Instead, these authors referred to [43], where bootstrap resampling with samples of intermediate size was recommended. This means that rather than conducting one test for a large sample, many tests for smaller samples are conducted and, hopefully, most tests would verify BL. To implement this recommendation ("small $n$ design"), we used weekly logbooks: There are in total 1132 weekly logbooks of the 20 animals with sample sizes of 65 distances, on average (for $95 \%$ of the logbooks, sample size varied between 31 and 74 distances). For these smaller samples (weekly logbooks), we used the Yates [44] continuity correction YCC, Equation (5):

$$
Y C C=\sum_{\text {digits }} \frac{(\mid \text { observed }- \text { theoretical } \mid-0.5)^{2}}{\text { theoretical }}
$$

As the critical value of each test statistic depends on sample size, we used a Monte Carlo simulation to assess whether our data fit $B L$; the computation used Mathematica [37]. This simulation was particularly important for our logbooks, as each logbook had a different size and, therefore, the test for $B L$ required a different critical value for each logbook. We first generated $1132 \mathrm{BL}$-distributed random samples with the same sizes as the observed logbooks. We then applied a certain test statistic for each of these sample-logbooks and recorded the 1132 results. As an example, for $\chi^{2}$ and for each simulated $B L$-distributed logbook, we computed the $p$-value from the chi-square distribution with eight degrees of freedom and used it to check if $B L$ was refuted (i.e., $p$-value below 0.05). To this end, we counted how many of the 1132 simulated logbooks refuted $B L$. We repeated this simulation 500 times. We thereby obtained a sample of 500 counts. We compared this sample with the observed count of refutations of $B L$ for our logbook data. To this end, we estimated a Poisson distribution for the sample of 500 counts, verified its goodness of fit using probability plots [45] and statistical tests [46] implemented in a Mathematica [37] function 
(DistributionFitTest), and used this distribution to compute the $p$-value for the hypothesis of a higher number of refutations than observed for the animal logbooks. For $p<0.05$, we concluded that the observed data were unlikely to fulfil $B L$.

As an additional test method, we computed Clopper-Pearson exact confidence intervals [47] for the frequencies of the leading digits for each animal-week. We used this method as it is suitable for small samples and does not make distribution assumptions. Reference [48] surveys several other conceivable statistical tests.

\section{Results}

When the data of each animal were considered separately, then, for 13 of the 20 individuals, the chi-square test refuted the null hypothesis that the data fit $B L$.

Table 1 confirms the "large $n$ problem" [38], as discussed above. For the large sample of all 73,393 distances, the chi-square test refuted $B L$ ( $p$-value $5 \times 10^{-30}$ for a higher $\chi^{2}$ than observed), whereas in terms of $M A D=0.0048$, the deviation of the data from $B L$ was barely discernible. However, in a simulation of $500 \mathrm{BL}$-distributed samples of size 73,393 each, much smaller values of $M A D$ were observed; $95 \%$ of the simulated $M A D$-values were below 0.00131 . Fitting a lognormal distribution to the sample of simulated $M A D$-values, $M A D>0.0048$ was unlikely $\left(p\right.$-value $\left.4.6 \times 10^{-10}\right)$.

Table 1. Overall count of leading digits for all 20 animals.

\begin{tabular}{cccccccccc}
\hline Digit: & $\mathbf{1}$ & $\mathbf{2}$ & $\mathbf{3}$ & $\mathbf{4}$ & $\mathbf{5}$ & $\mathbf{6}$ & $\mathbf{7}$ & $\mathbf{8}$ & $\mathbf{9}$ \\
\hline Observed: & 21,473 & 13,461 & 9516 & 7669 & 5941 & 4691 & 3976 & 3576 & 3090 \\
Theoretical: & $22,093.5$ & $12,923.8$ & 9169.6 & 7112.5 & 5811.4 & 4913.4 & 4256.2 & 3754.2 & 3358.3 \\
\hline
\end{tabular}

Next, we focused on the analysis of the weekly logbooks of all animals.

The chi-square test refuted BL for 9\% (99) of the 1132 logbooks. We used Monte Carlo simulations to assess if this outcome supported $B L$. Repeating the computations with 500 sets of 1132 simulated BL-distributed logbooks each, we obtained a sample of 500 simulated counts of refutations. This sample was approximately Poisson distributed with a mean value of 56 refutations. Figure 1 plots the probability plot to assess the goodness of fit of the Poisson distribution. For this distribution, a count of more than 99 refutations amongst 1132 simulated $B L$-distributed logbooks was unlikely ( $p$-value $10^{-7}$ ). Thus, although the chi-square test supported $B L$ for most weekly samples, the number of observed refutations was too large to be explained by spurious tests alone.

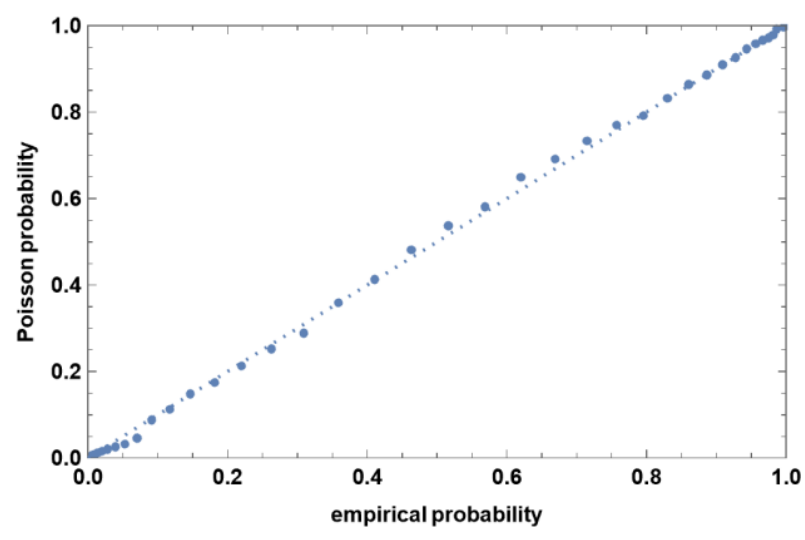

(a)

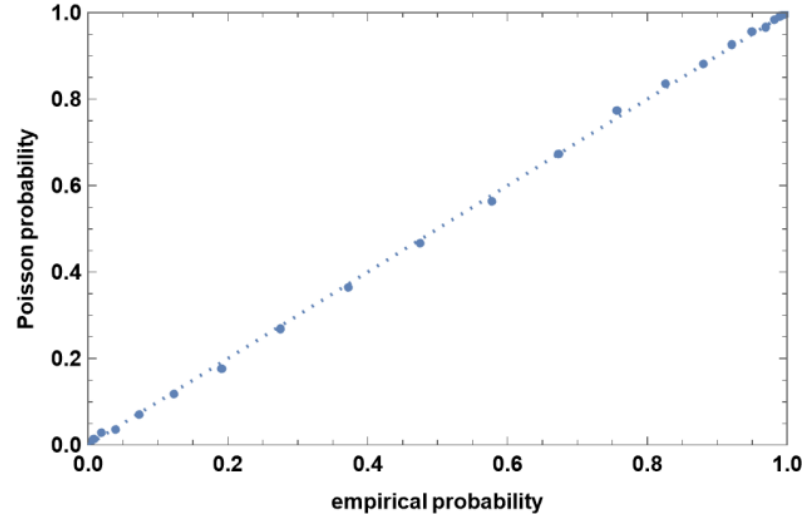

(b)

Figure 1. Probability plots comparing the simulated counts of refutations for $B L$-distributed logbooks with a Poisson distribution for (a) refutations using $\chi^{2}$; (b) refutations using YCC; plots using Mathematica [30]. 
For the Yates correction, BL was refuted for 3\% (33) of the 1132 logbooks (computing the $p$-value from the chi-square distribution with eight degrees of freedom). However, a sample of 500 simulated counts of refutations was approximately Poisson distributed with a mean value of 15 refutations (Figure 1 for the probability plot). For this Poisson distribution, a count of more than 33 refutations was unlikely ( $p$-value 0.00002 ). Hence again, the number of observed refutations was too large to be explained by spurious tests alone.

$M A D$ supported $B L$ (meaning: $M A D \leq 0.05$ ), except for $4.8 \%$ (54) of the 1132 logbooks. By comparison, a sample of 500 simulated counts of refutations $(M A D>0.05)$ was approximately Poisson distributed with a mean value of 31 refutations, and for this distribution, the occurrence of more than 54 logbooks with $M A D>0.05$ was unlikely ( $p$-value 0.0001). Hence, several of the observed refutations were not spurious.

As Table 1 suggests, the digit 1 led less frequently than expected from $B L$. The confidence intervals for the weekly logbooks confirmed this observation. For $7 \%$ of logbooks, the observed frequency of 1 as a leading digit was outside the $95 \%$ confidence interval for this frequency under the assumption of $B L$. For digits $2,3, \ldots$, and 9 , the corresponding frequencies were $3 \%, 2 \%, 3 \%, 2 \%, 3 \%, 4 \%, 6 \%$, and $8 \%$, respectively. For $71 \%$ of logbooks, the frequencies of all leading digits were within the confidence intervals.

An analysis of the frequencies of 1 s versus non-1s as leading digits confirmed the deficiencies of leading 1s. Using the chi-square test (one degree of freedom) for 7\% (81) logbooks, a significant deviation from the $B L$-frequency was noted ( $p$-value below 0.05). A sample of 500 simulated counts of refutations was approximately Poisson distributed with a mean value of 57 refutations. For this distribution, more than 81 significant deviations were unlikely ( $p$-value 0.001 ).

Similar results were obtained when the distance was measured in two dimensions using Equation (2) without the z-coordinate, or when monthly logbooks were considered.

\section{Discussion and Conclusions}

In social sciences, $B L$ is an established test for data corruption. This paper applied this test for the first time to telemetry data that track the movements of animals. We studied 1132 weekly logbooks of 20 individuals of wild red deer that, over four years, recorded the lengths of their walks. These data displayed a BL-like distribution of the leading digits. Nevertheless, $B L$ had only limited evidence, as the data did not follow BL perfectly. For $9 \%$ of the weekly logbooks, the chi-square test refuted the BL-hypothesis. A Monte Carlo simulation confirmed that this deviation from $B L$ could not be explained by spurious tests alone, where deviations from $B L$ occurred by chance. This finding was confirmed by multiple tests, including the mean absolute deviation $M A D$.

This finding does not refute the hypothesis of $B L$-distributed logbooks, because we are not sure if our implicit assumptions (e.g., no human impact on the animals, no location error) were satisfied for all animals during the whole study period. Kaprun is a tourism hotspot with peaks in winter (skiing) and summer (hiking), and deer are expected to avoid the crowded areas. Behavioral changes are conceivable during the hunting season. The mating season may also change the movement pattern. In winter, restrictions in the movement are possible due to deep snow. Considering these possible impacts, movements of the deer during certain periods of our study may have been atypical. However, there were too few weeks (99) with significant deviations from BL to draw valid conclusions about the reasons for these deviations and to distinguish systematic from spurious deviations.

Thus, in exploring $B L$ for animal movement, the approach using weekly logbooks may be suitable to study the impact of human and natural pressures, where data about such impacts on animal behavior are not accessible by other means. To explore this research question, in a forthcoming study (duration about one year), we will consider weekly logbooks in wildlife and in restricted areas (game preserves). We think that this should result in clear distinctions in the first digit frequencies. Further, we hypothesize that distances moved by wild animals, irrespective of species, should satisfy $B L$. 
Supplementary Materials: The following are available online at https://www.mdpi.com/article/10 $.3390 /$ stats4040055/s1, Table S1 is an Excel file that summarizes the data, Table S2 is an Excel file that summarizes the above computations, and Table S3 is one of twenty Excel files with raw data.

Author Contributions: Conceptualization, L.P., N.B. and M.K.; Methodology, L.P., P.G., N.B., K.H. and M.K.; Formal analysis, L.P.; Resources, P.G. and K.H.; Data Curation, L.P., P.G. and M.K.; Writing - Original Draft Preparation, N.B. and M.K.; Writing - Review \& Editing, L.P., P.G., N.B., K.H. and M.K. The paper is based on the master thesis [35] of the first author. The other authors provided the data $(2,3)$, guided the thesis work and/or examined the thesis $(3,4,5)$. All authors have read and agreed to the published version of the manuscript.

Funding: This research was funded by the Austrian Research Promotion Agency (FFG, project number: 848464), Gletscherbahnen Kaprun AG, and the owner of the study site, Gutsverwaltung Fischhorn GmbH \& Co KG. The APC was funded by BOKU.

Institutional Review Board Statement: Data collection by collaring (and prior immobilization) of deer complied with federal and state laws, was approved by the ethics committee of the University of Veterinary Medicine, Vienna, and was authorized by the province of Salzburg (official notification numbers 20401-01072/4/10-2015 and 20401-01070/21/10-2015).

Data Availability Statement: The data are provided as Supplementary Material.

Acknowledgments: We appreciate the support by the professional hunters that were involved in the study. Further, we are thankful to Hanno Gerritsmann, Beatrix Sternath, and Franz Hölzl for their expertise during the collaring of red deer, and to Leopold Obermair for supervising the data collection at the beginning of the project. Brady Mattsson of the Institute of Wildlife Biology and Game Management was so kind to check the language. The authors appreciate the comments by the reviewers and editors for this journal.

Conflicts of Interest: The authors declare no conflict of interest. The funders had no role in research for the present paper.

\section{References}

1. Newcomb, S. Note on the frequency of use of different digits in natural numbers. Am. J. Math. 1881, 4, 39-40. [CrossRef]

2. Benford, F.A. The law of anomalous numbers. Proc. Am. Philos. Soc. 1938, 78, 551-572.

3. Hill, T.P.; Berger, A. Benford Online Bibliography. Available online: www.benfordonline.net/ (accessed on 25 September 2021).

4. Nigrini, M.J. Forensic Analytics: Methods and Techniques for Forensic Accounting Investigations; Wile: New York, NY, USA, 2020.

5. Varian, H.R. Benford's Law. Am. Stat. 1970, 26, 65-66.

6. Carslaw, C.A.P.N. Anomalies in Income Numbers: Evidence of Goal Oriented Behavior. Account. Rev. 1988, 63, $321-327$.

7. Nigrini, M.J. Taxpayer compliance application of Benford's law. J. Am. Tax. Assoc. 1996, 18, 72-92.

8. Akinadewo, I.S.; Akinkoye, E.Y. Tax Evasion Detection in Nigeria: Analysis of the Specific Forensic Accounting Techniques Used. Bus. Manag. Rev. 2020, 11, 131-139.

9. Beber, B.; Scacco, A. What the Numbers Say: A Digit-Based Test for Election Fraud. Political Anal. 2012, 20, 211-234. [CrossRef]

10. Buyse, M.; George, S.L.; Evans, S.; Geller, N.L.; Edler, L.; Hutton, J. The Role of Biostatistics in the Prevention, Detection and Treatment of Fraud in Clinical Trials. Stat. Med. 1999, 18, 3435-3451. [CrossRef]

11. Hindls, R.; Hronová, S. Benford's Law and Possibilities for Its Use in Governmental Statistics. Statistika 2015, 95, 54-64.

12. Shao, L.; Ma, B.Q. Empirical mantissa distributions of pulsars. Astropart. Phys. 2010, 33, 255-262. [CrossRef]

13. Pain, J.C. Regularities and symmetries in atomic structure and spectra. High Energy Density Phys. 2013, 9, 392-401. [CrossRef]

14. Arita, M. Scale-freeness and biological networks. J. Biochem. 2005, 138, 1-4. [CrossRef]

15. Campanario, J.M.; Coslado, M.A. Benford's law and citations, articles and impact factor of scientific journals. Scientometrics 2011, 88, 421-423. [CrossRef]

16. Margellou, A.G.; Pomonis, P.J. Benford's law, Zipf's law and the pore properties in solids. Microporous Mesoporous Mater. 2020, 292, 109735. [CrossRef]

17. Salsburg, D. Digit Preference in the Bible. Chance 1997, 10, 46-48. [CrossRef]

18. Gómez-Camponovo, M.; Moreno, J.; Idrovo, A.J.; Páez, M.; Achkar, M. Monitoring the Paraguayan epidemiological dengue surveillance system using Benford's law. Biomédica 2016, 36, 583-592. [CrossRef]

19. Sambridge, M.; Jackson, A. National COVID numbers-Benford's law looks for errors. Nature 2020, 581, 384. [CrossRef]

20. Hill, T.P. The significant-digit phenomenon. Am. Math. Mon. 1995, 102, 322-327. [CrossRef]

21. Hill, T.P. A statistical derivation of the significant-digit law. Stat. Sci. A Rev. J. Inst. Math. Stat. 1995, 10, 354-363. [CrossRef]

22. Berger, A.; Hill, T.P. An Introduction to Benford's Law; Princeton University Press: Princeton, NJ, USA, 2015.

23. Engel, H.A.; Leuenberger, C. Benford's law for exponential random variables. Stat. Probab. Lett. 2003, 63, 361-365. [CrossRef]

24. Lemons, D.; Lemons, N.; Peter, W. First Digit Oscillations. Stats 2021, 4, 595-601. [CrossRef] 
25. Pietronero, L.; Tosatti, E.; Tosatti, V.; Vespignanic, A. Explaining the uneven distribution of numbers in nature: The laws of Benford and Zipf. Phys. A 2001, 293, 297-304. [CrossRef]

26. Goodman, W. The promises and pitfalls of Benford's law. Significance 2016, 13, 38-41. [CrossRef]

27. Viswanathan, G.M.; Buldyrev, S.V.; Havlin, S.; da Luz, M.G.E.; Raposo, E.P.; Stanley, H.E. Optimizing the success of random searches. Nature 1999, 401, 911-914. [CrossRef]

28. Mårell, A.; Ball, J.; Hofgaard, A. Foraging and movement paths of female reindeer: Insights from fractal analysis, correlated random walks, and Lévy flights. Can. J. Zool. 2002, 80, 854-865. [CrossRef]

29. Schürger, K. Lévy Processes and Benford's Law. In Benford's Law: Theory and Applications; Miller, S.J., Ed.; Princeton University Press: Princeton, NJ, USA, 2015; pp. 135-173.

30. Edwards, A.M.; Phillips, R.A.; Watkins, N.W.; Freeman, M.P.; Murphy, E.J.; Afanasyev, V.; Buldyrev, S.V.; da Luz, M.G.E.; Raposo, E.P.; Stanley, H.E.; et al. Revisiting Lévy flight search patterns of wandering albatrosses, bumblebees and deer. Nature 2007, 449, 1044-1048. [CrossRef]

31. Berger, A.; Bunimovich, L.A.; Hill, T.P. One-dimensional dynamical systems and Benford's law. Trans. Am. Math. Soc. 2004, 357, 197-219. [CrossRef]

32. Brähler, G.; Bensmann, M.; Jakobi, H.R. Das Benfordsche Gesetz und Seine Anwendbarkeit bei der Digitalen Prüfung von Fahrtenbüchern; Ilmenauer Schriften zur Betriebswirtschaftslehre; Technische Universität: Ilmenau, Germany, 2011.

33. Sambridge, M.; Tkalčić, H.; Jackson, A. Benford's Law in the natural sciences. Geophys. Res. Lett. 2010, 37, L22301-L22306. [CrossRef]

34. Griesberger, P.; Hackländer, K. Integrales Rotwildmanagement: Strategievernetzung Zwischen Forst-, Land-, Jagd- und Tourismuswirtschaft; FFG Project Number 848464; Final Project Report; BOKU: Vienna, Austria, 2018.

35. Pröger, L. Anwendbarkeit des Benford-Gesetzes auf Bewegungsdaten von Wildtieren. Master's Thesis, Institute of Mathematics, Department of Integrative Biology and Biodiversity Research, University of Natural Resources and Life Sciences, Vienna, Austria, 2021.

36. Department of Defense. Its definition and relationships with local geodetic systems. In World Geodetic System 1984; Technical Report; DoD: Rockville, MD, USA, 1991.

37. Wolfram Research Inc. Mathematica; Version 12.3; Wolfram Research Inc.: Champaign, IL, USA, 2021.

38. Lindley, D.V. A Statistical Paradox. Biometrika 1957, 44, 187-192. [CrossRef]

39. Kossovsky, A.E. On the Mistaken Use of the Chi-Square Test in Benford's Law. Stats 2021, 4, 419-453. [CrossRef]

40. Nigrini, M.J. Audit Sampling Using Benford's Law: A Review of the Literature with Some New Perspectives. J. Emerg. Technol. Account. 2017, 14, 29-46. [CrossRef]

41. Druică, E.; Oancea, B.; Vâlsan, C. Benford's law and the limits of digit analysis. Int. J. Account. Inf. Syst. 2018, 31, 75-82. [CrossRef]

42. Cerqueti, R.; Lupi, C. Some New Tests of Conformity with Benford's Law. Stats 2021, 4, 745-761. [CrossRef]

43. Bickel, P.J.; Götze, F.; van Zwet, W.R. Resampling Fewer Than $n$ Observations: Gains, Losses, and Remedies for Losses. Stat. Sin. 1997, 7, 1-31.

44. Yates, F. Contingency table involving small numbers and the $\chi^{2}$ test. Suppl. J. R. Stat. Soc. 1934, 1, 217-235. [CrossRef]

45. Chambers, J.; Cleveland, W.; Kleiner, B.; Tukey, P. Graphical Methods for Data Analysis; Chapman \& Hall: Boca Raton, FL, USA, 2017.

46. D'Agostino, R.B.; Stephens, M.A. Goodness-of-Fit.-Techniques; Taylor \& Francis (Informa): London, UK, 1986.

47. Clopper, C.; Pearson, E.S. The use of confidence or fiducial limits illustrated in the case of the binomial. Biometrika 1934, 26, 404-413. [CrossRef]

48. Joenssen, D.W. Testing for Benford's Law: A Monte Carlo Comparison of Methods; Working Paper; No. 2545243; SSRN: Rochester, NY, USA, 2015. 